OPEN ACCESS

Edited by:

Liang Wu,

Chongqing University, China

Reviewed by:

Bo Song,

Southwest University, China

Jiejun He,

Guizhou Institute of Technology, China

${ }^{*}$ Correspondence:

Zhiguo An

anzhiguo@cqjtu.edu.cn

Specialty section:

This article was submitted to

Environmental Degradation of

Materials,

a section of the journal

Frontiers in Materials

Received: 10 July 2021

Accepted: 31 July 2021

Published: 18 August 2021

Citation:

Gao Z, Sun C, Du L, Yang D, Zhang X

and $A n Z$ (2021) The Corrosion

Resistance of Graphene-Modified Oily

Epoxy Coating on AZ31

Magnesium Alloys.

Front. Mater. 8:739334.

doi: 10.3389/fmats.2021.739334

\section{The Corrosion Resistance of Graphene-Modified Oily Epoxy Coating on AZ31 Magnesium Alloys}

\author{
Zhengyuan Gao, Chengjin Sun, Lianteng Du, Dong Yang, Xiang Zhang and Zhiguo An* \\ School of Mechatronics and Vehicle Engineering, Chongqing Jiaotong University, Chongqing, China
}

In order to enhance the corrosion resistance of AZ31 magnesium alloy, graphene-modified oily epoxy resin coating (G/OEP) were prepared on the surface of magnesium alloy. SEM observations show that graphene has fewer surface defects, and can significantly improve the surface quality of the coating and reduce defects. Fl-TR testing shows that coating are mainly composed of epoxy resin (polyurethane) and its corresponding curing agent. Electrochemical testing shows that the coating can provide good corrosion protection for magnesium alloy. Compared with the corrosion current density of magnesium alloy of $6.20 \times 10^{-7} \mathrm{~A}_{\mathrm{cm}}{ }^{2}$, the G/OEP can significantly reduce the corrosion current density to $6.96 \times 10^{-12} \mathrm{~A} / \mathrm{cm}^{2}$. Analysis of the morphology of the coating after electrochemical corrosion found that graphene can improve the shielding ability of the coating to corrosive media, and reduce the damage of corrosion to the coating structure, and enhance the corrosion resistance of the coating. The content of graphene for excellent corrosion resistance of coating during this experiment is $0.6 \mathrm{wt} \%$. The graphene can fill the defects generally in the coating during the curing process to prevent substrate from penetration of corrosive media caused by the density and hydrophobicity of coating are increased.

Keywords: AZ31 magnesium alloy, graphene, corrosion resistance, oily epoxy resin, coating

\section{INTRODUCTION}

In recent decades, due to the increasingly serious environmental problems, magnesium alloy materials are extremely suitable for material substitution standards for energy-saving and lightweight design. Therefore, they have been widely used in many fields such as automobiles and aerospace (Tekumalla et al., 2014; Dziubińska et al., 2016; Zeng et al., 2018; Ramalingam et al., 2019; Song et al., 2020). However, magnesium is extremely reactive. The standard electrode potential of magnesium is $2.37 \mathrm{~V}$, which is very easy to corrode. The naturally formed $\mathrm{MgO} / \mathrm{Mg}(\mathrm{OH})_{2}$ has a loose and porous structure, resulting in a weak corrosion resistance of the magnesium alloy itself (Song and Atrens, 2003; Song, 2005; Chu et al., 2019; Chen et al., 2019).

In response to this problem, epoxy resin organic coating is the most economical and effective method from an industrial point of view (Shi et al., 2012; He et al., 2014; Guo et al., 2020). It's easy to operate, low cost, and has natural advantages in industrial applications (Jin et al., 2015; Ou et al., 2020). At present, oily coatings have good film-forming properties, strong water resistance and excellent corrosion resistance. Although epoxy resin has shown excellent anti-corrosion protection for magnesium alloy matrix, it is affected by the cross-linking density of epoxy bonds, and the coating will be affected in the later curing and cross-linking process.

Defects such as holes and cracks are generated, thereby reducing the corrosion protection ability of the substrate. Therefore, in recent years, researchers have done a lot of research in this direction, 
the main method is to add corrosion inhibitor fillers to the coating materials (Dong et al., 2013; Deyab et al., 2016; Xie et al., 2019; Rahman et al., 2019). Graphene has excellent corrosion inhibition performance among many corrosion inhibitor fillers (Zhang et al., 2015; Hao et al., 2018; Xia et al., 2018; Ziat et al., 2020). Graphene is a carbon material with a twodimensional structure, and has excellent physical properties and stable chemical properties. The special structure can have extremely high resistance to oxygen and water permeability (Zhao et al., 2013; Wu et al., 2018; Zhou et al., 2018; Cui et al., 2019; Ding et al., 2019). Compared with other methods, the oily epoxy resin coating modified by the graphene is stable in the corroded state for the substrate. Moreover, the inhibition effect can be improved by the dispersion in oily epoxy resin and the hydrophobicity is better than waterborne epoxy resin. As soon as these advantages were discovered, they received extremely high attention from research scholars. Chen et al. modified graphene carbonitride nanosheets (g-C3N4) and graphene through $\pi-\pi$ bond interactions to increase the dispersion performance of graphene in epoxy resin coatings, and significantly improve the corrosion resistance of the coating (Chen et al., 2020).

At present, there are few studies on using graphene modified oily epoxy resin coatings to improve the corrosion resistance of magnesium alloys. Therefore, this article explores the effect of the coating on the corrosion resistance of AZ31 magnesium alloy by modifying oily epoxy resin coatings with different contents of graphene.

\section{MATERIALS AND METHODS}

\section{Materials}

This experiment used a deformed AZ31B magnesium alloy sheet as the substate material, and its composition is shown in Table 1.

The sample preparation process is as follows: the magnesium alloy sheet was cut into many samples of $20 \mathrm{~mm} \times 20 \mathrm{~mm} \times 10 \mathrm{~mm}$ with a wire cutting machine, and then the cutting fluid on the sample surface was removed with acetone solution in the ultrasonic cleaner, and then the surface was polished step by step using 500, 800, 1200, 2000 and 3,000 mesh alumina abrasive sandpapers, respectively. After there are no obvious scratches on the surface of the samples, clean them with alcohol, dry them with hot air, and put them in a drying dish for use.

The graphene used in this experiment was purchased from Changzhou Sixth Element Material Technology Co., Ltd. Oily bisphenol A epoxy resin paint and phenolic amine oily epoxy resin curing agent were purchased from Guangzhou Tuan Anticorrosion Technology Co., Ltd.

TABLE 1 | Main components of AZ31B magnesium alloy/wt\%.

\begin{tabular}{cccccccc}
\hline Element & Al & Zn & Mn & Cu & Ni & Fe & Mg \\
\hline Content & 3.007 & 1.054 & 0.488 & 0.001 & 0.002 & 0.004 & Bal
\end{tabular}

\section{Coating Preparation}

The oil-based epoxy resin coating was modified with four different contents of graphene, and the weight ratio of graphene to the epoxy resin coating was $0 \mathrm{wt} \%, 0.1 \mathrm{wt} \%$, $0.3 \mathrm{wt} \%$, and $0.6 \mathrm{wt} \%$, respectively. The specific operation method of coating preparation is as follows: according to the corresponding ratio, the graphene of different weights and $50 \mathrm{~g}$ oily epoxy resin paint were stirred with a mechanical stirrer at a high speed for $30 \mathrm{~min}$. After stirring until the mixture is uniform, mix the mixed paint and the curing agent according to the ratio of $3: 1$. Then continued to mechanically stir the mixed paint until the mixing was uniform, and finally used a wool brush to coat the mixed paint on the surface of the AZ31 magnesium alloy, and cured at room temperature for 14 days to obtain a coating with a dry film thickness of $600 \pm 20 \mu \mathrm{m}$. For the convenience of analysis, the graphene modified oily epoxy resin coating is marked as G/OEP-0 wt \%, G/OEP-0.1 wt $\%$, G/OEP-0.3 wt $\%$, G/OEP-0.6 wt\%.

\section{Test Method}

JSM-6610 scanning electron microscope was used to observe the surface morphology of graphene and coating. FTIR analysis was used to characterize the structure and composition of graphene and the coating, the specific working parameters were the detection range of $4,000 \mathrm{~cm}^{-1}-400 \mathrm{~cm}^{-1}$ and the resolution of $4 \mathrm{~cm}^{-1}$. The CHI660E series electrochemical workstation was used to test the anti-corrosion performance, and the classic three-electrode test system was used; the magnesium alloy substrate and the coating sample were used as the working electrode, and the working area was $1 \mathrm{~cm}^{2}$, the counter electrode was a platinum electrode, the reference electrode was a saturated glycerin mercury electrode, the test solution was 3.5 $\mathrm{wt} \% \mathrm{NaCl}$ solution, e tests were performed at room temperature. All samples were tested for open circuit potential (OCP) multiple times until the potential stabilized, and then the potentiodynamic polarization curve was tested. The specific test parameters were: voltage sweep interval of -3 to $1 \mathrm{~V}$ and sweep speed of $1 \mathrm{mV} / \mathrm{s}$.

\section{RESULTS AND DISCUSSION}

\section{Characterization of Graphene and Coatings}

Figure 1 is a picture of the microscopic morphology of graphene. From Figure 1A, it can be seen that graphene has small flakes that exist in a single-layer structure, and there are also large flakes that agglomerate into a multilayer structure. These agglomerations are caused by the interaction of $\pi-\pi$ bonds between graphene, which will also have a certain impact on the dispersion properties of graphene in coatings. It can also be seen from the figure that the size of single-layer and multi-layer graphene generally does not exceed $20 \mu \mathrm{m}$, and the size of single-layer graphene can reach $10 \mu \mathrm{m}$ or less. In addition, as shown in Figure 1B, the sheet-like structure of graphene can be further clearly seen, and the surface is slightly wrinkled, indicating that the surface structure of graphene has low defects.

Figure 2 shows the test results of graphene Fourier infrared spectroscopy. It can be seen from the figure that graphene mainly 

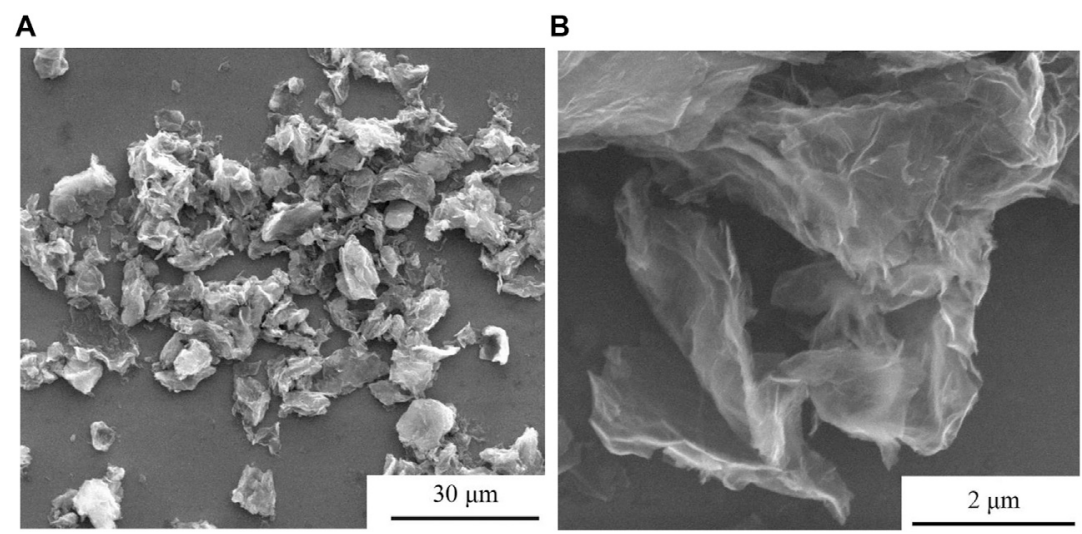

FIGURE 1 | Graphene micro-topography under different magnifications: (A) 2,400 times, (B) 40,000 times.

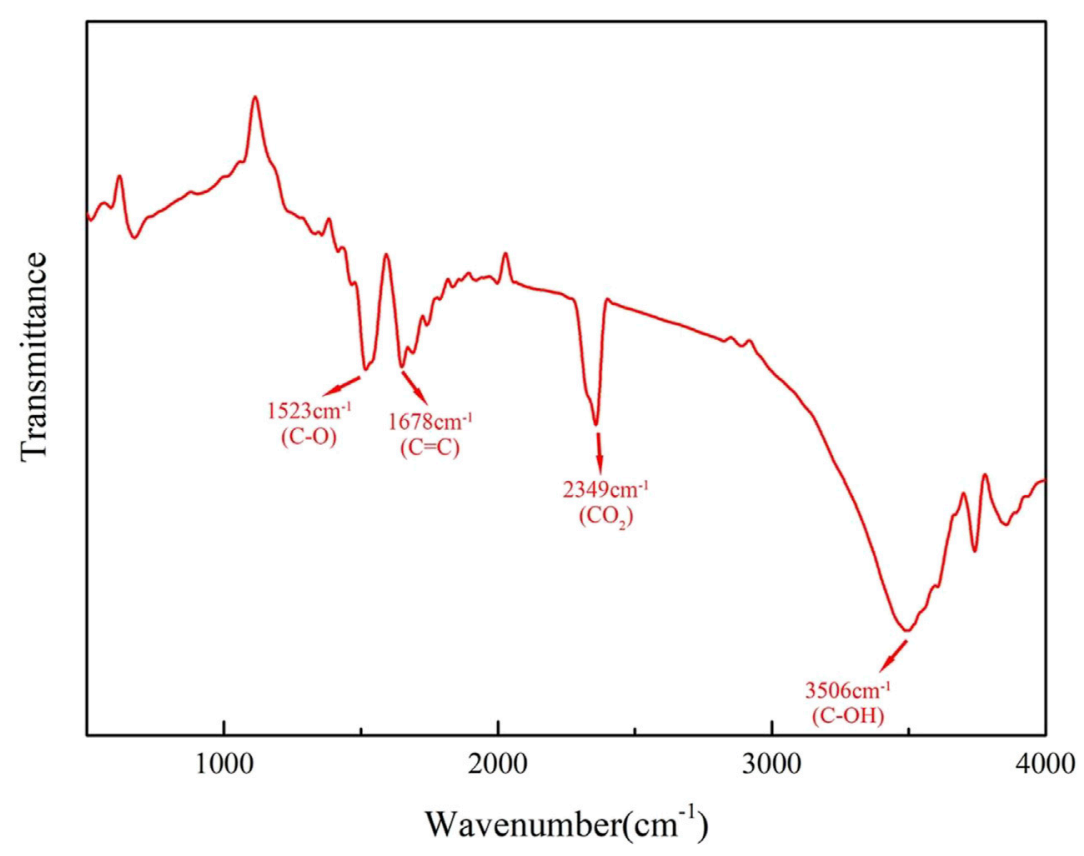

FIGURE 2 | Graphene FI-TR test spectrum.

contains four peaks in the spectrum, of which the peak at $1,523 \mathrm{~cm}^{-1}$ corresponds to the tensile vibration of the $\mathrm{C}-\mathrm{O}$ bond in the epoxy group. The peak corresponding to $1678 \mathrm{~cm}^{-1}$ is related to the vibration of the $\mathrm{C}=\mathrm{C}$ bond of the benzene ring. The peak at $2349 \mathrm{~cm}^{-1}$ is due to the symmetrical vibration of $\mathrm{CO} 2$ in the air inside the Fourier test space. The absorption peak at $3,506 \mathrm{~cm}^{-1}$ is caused by the $\mathrm{C}-\mathrm{OH}$ bond (Ye et al., 2020).

The FTIR spectrum of the oily epoxy resin coating is shown in Figure 3. Among them, the absorption peaks of methyl and methylene on the molecular chain of epoxy resin appear near $2,900 \mathrm{~cm}^{-1}$ and $2,800 \mathrm{~cm}^{-1}$, respectively. The absorption peak near $1,250 \mathrm{~cm}^{-1}$ corresponds to the vibration of the $\mathrm{C}=\mathrm{C}$ bond in the benzene ring. The absorption peaks at $1,510 \mathrm{~cm}^{-1}$ and $1,480 \mathrm{~cm}^{-1}$ correspond to the vibration of the $\mathrm{N}-\mathrm{H}$ and $\mathrm{C}-\mathrm{N}$ bonds in the phenalkamine curing agent, respectively. The absorption peak at $1,010 \mathrm{~cm}^{-1}$ is derived from the epoxy group in epoxy resin. The absorption peak at $1,640 \mathrm{~cm}^{-1}$ is the carbonyl group (Siva et al., 2014; Wang et al., 2018).

Figure 4 is a picture of the micro morphology of modified oily epoxy resin coatings with different contents of graphene. It can be seen from Figure 4A that when the graphene corrosion inhibitor filler is not added, the microstructure shows that the coating surface has more defects and larger roughness, which may be caused by the rupture of bubbles generated during the curing process. Figure 4B shows that when $0.1 \mathrm{wt} \%$ graphene is added, 


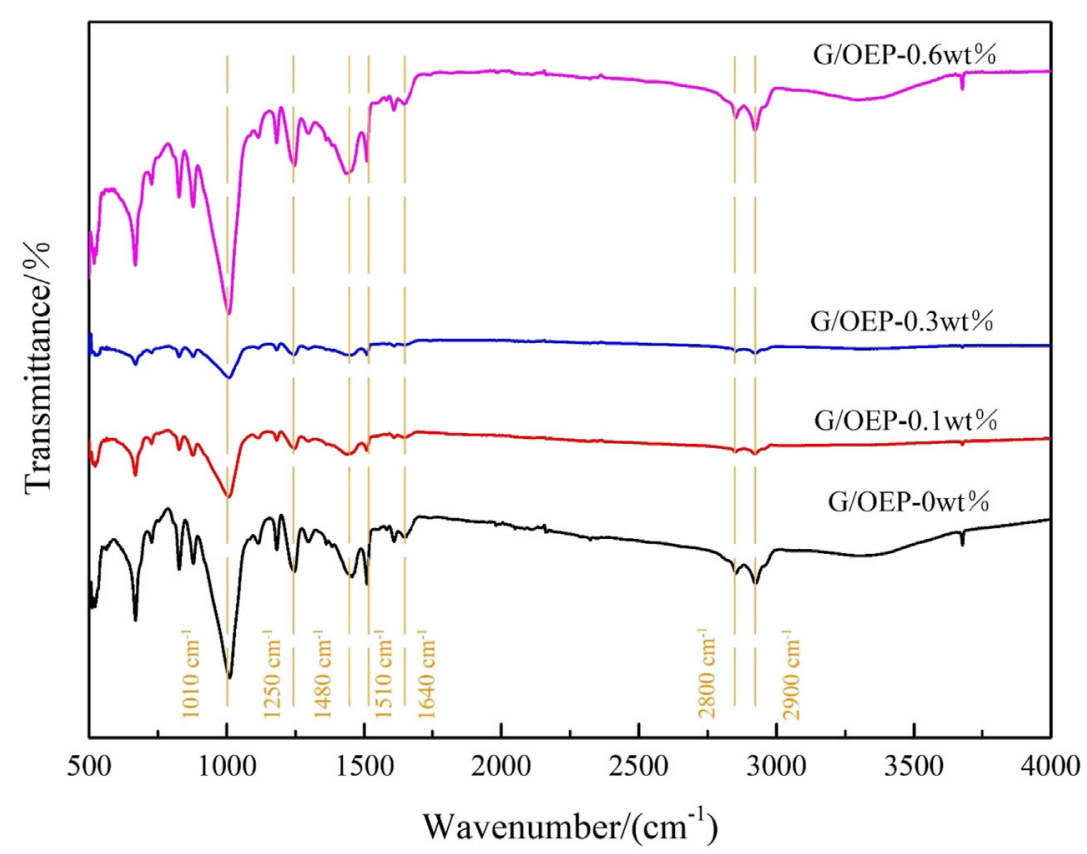

FIGURE 3 | Graphene FI-TR test spectrum.

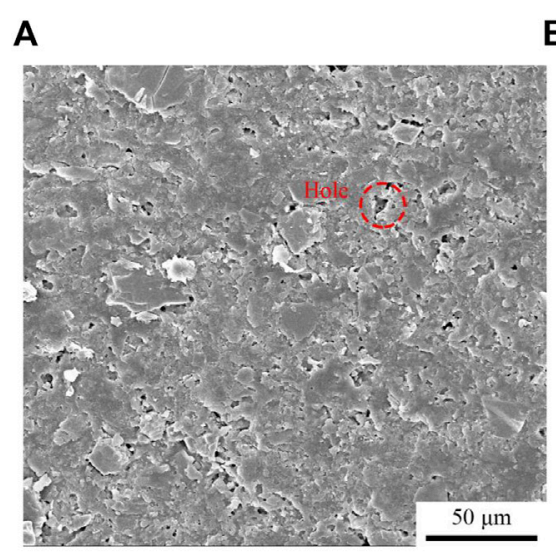

B

C
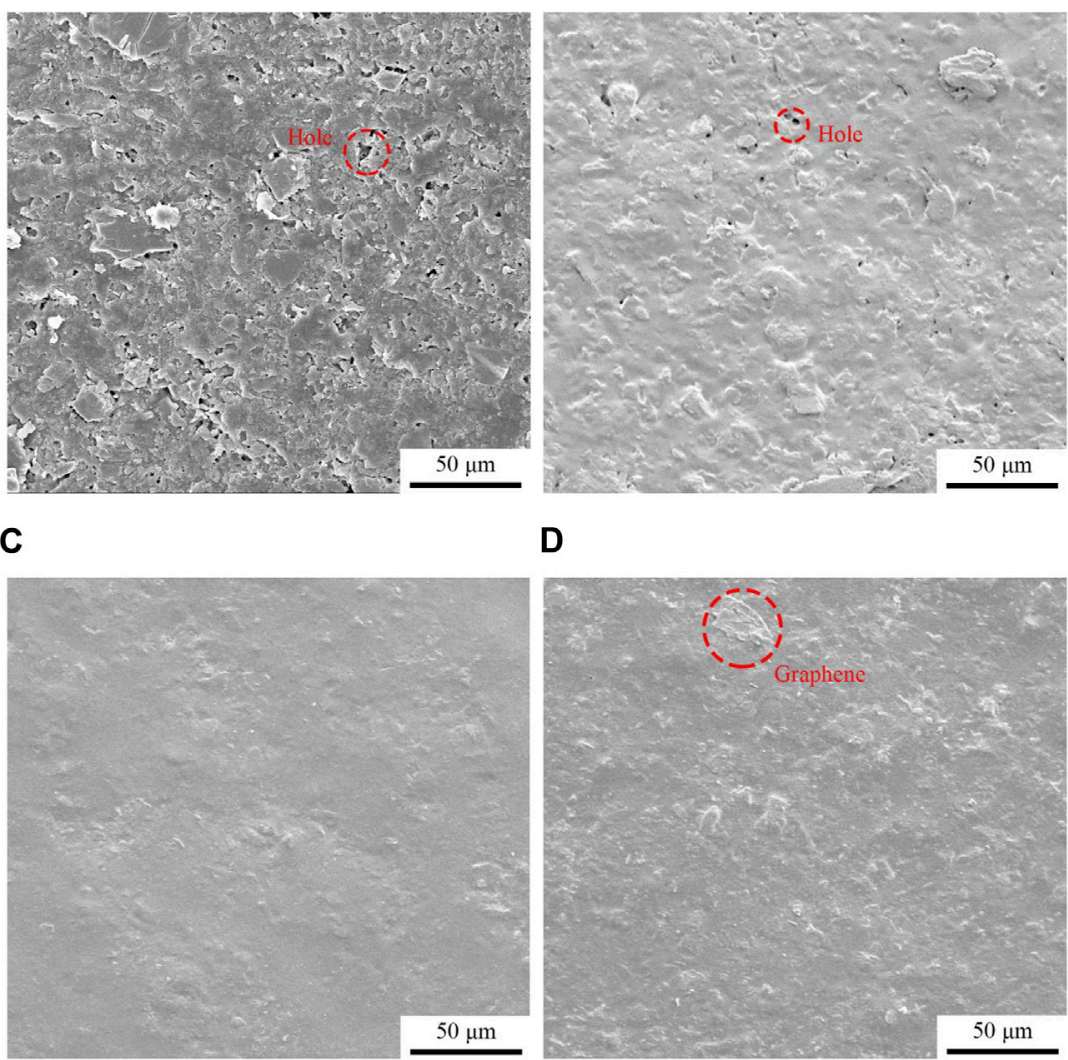

D

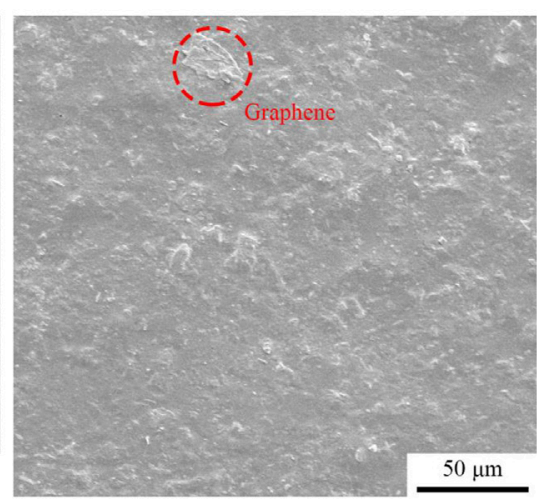

FIGURE 4 | Micro morphology of graphene modified oily epoxy resin coating: (A) G/OEP-0 wt\%, (B) G/OEP-0.1 wt\%, (C) G/OEP-0.3 wt\%, (D) G/OEP-0.6 wt\%. 


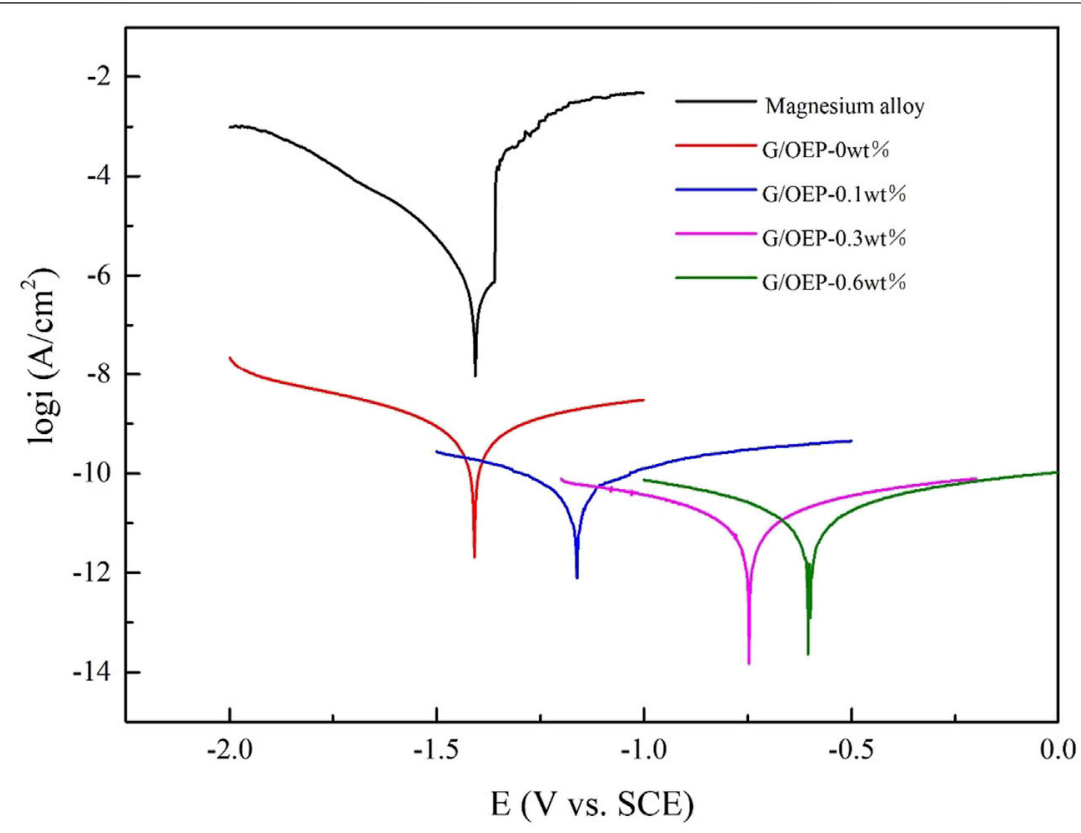

FIGURE 5 | Potential polarization curve of magnesium alloy and coating

TABLE 2 | Related parameters of potentiodynamic polarity curve.

Sample

Corrosion current density $\left(\mathrm{A} / \mathrm{cm}^{2}\right)$

Magnesium alloy

G/OEP-0 wt\%

G/OEP-0.1 wt\%

G/OEP-0.3 wt\%

G/OEP-0.6 wt\%
Corrosion potential(V)

$-1.47$

$-1.49$

$-1.16$

$-0.75$

$-0.60$

the surface defects and roughness of the coating are significantly reduced, and the holes and pits are also significantly reduced. This is because with the addition of graphene, the two-dimensional flaky structure can well fill the holes and pits caused by the bubble burst during the coating curing, which greatly improves the surface defects of the coating. As the graphene content continues to increase, when it reaches $0.3 \mathrm{wt} \%$, Figure $4 \mathrm{C}$ shows that the coating surface is relatively smooth, with almost no obvious holes visible, and the coating has a higher surface quality, which is because as the graphene content continues to increase, the graphene filler has reached a better dispersion state inside the coating. Using its own structural characteristics, it almost covers the entire coating surface, which can well fill the coating surface defects. However, Figure 4D shows that when the content of graphene filler reaches $0.6 \mathrm{wt} \%$, the surface quality of the coating decreases, but no obvious defects appear. Analysis believes that this is due to the fact that as the content of graphene increases, the mutual attraction between $\pi-\pi$ bonds leads to a decrease in the dispersion quality of graphene inside the coating, and agglomeration begins to occur during the curing process of the coating. The

agglomerated graphene has been exposed on the surface of the coating, which will prevent the graphene from being well dispersed on the entire coating surface to fill the defects, and the agglomerated graphene will increase the surface roughness of the coating.

\section{Coating Electrochemical Performance}

Figure 5 shows the potentiodynamic polarization curves of magnesium alloys and coatings. Table $\mathbf{2}$ lists the electrochemical parameters, including specific values of corrosion current density and corrosion potential. Since the corrosion potential is greatly affected by environmental factors, the corrosion current density is generally used to judge the corrosion resistance of the test sample. The smaller the corrosion current density, the better the corrosion resistance. It can be seen from Table 2 that the corrosion current density of the magnesium alloy matrix is $6.20 \times 10^{-7} \mathrm{~A} / \mathrm{cm}^{2}$, and the corrosion current density of the oily epoxy resin coating is lower than that of the magnesium alloy. It shows that the coating can significantly improve the corrosion resistance of magnesium alloys. The corrosion current density of G/OEP$0.6 \mathrm{wt} \%$ is the lowest, reaching $6.96 \times 10^{-12} \mathrm{~A} / \mathrm{cm}^{2}$, which is 5 orders of magnitude lower than that of the magnesium alloy matrix.

In order to facilitate the analysis of the influence of different contents of graphene on the corrosion resistance of the coating. Figure $\mathbf{6}$ shows the changing trend of the corrosion current density of the oily epoxy resin coating with different graphene content. It can be seen from the figure that with the addition of graphene, the corrosion resistance of the coating has been significantly improved. The corrosion current density of the coating is reduced by 


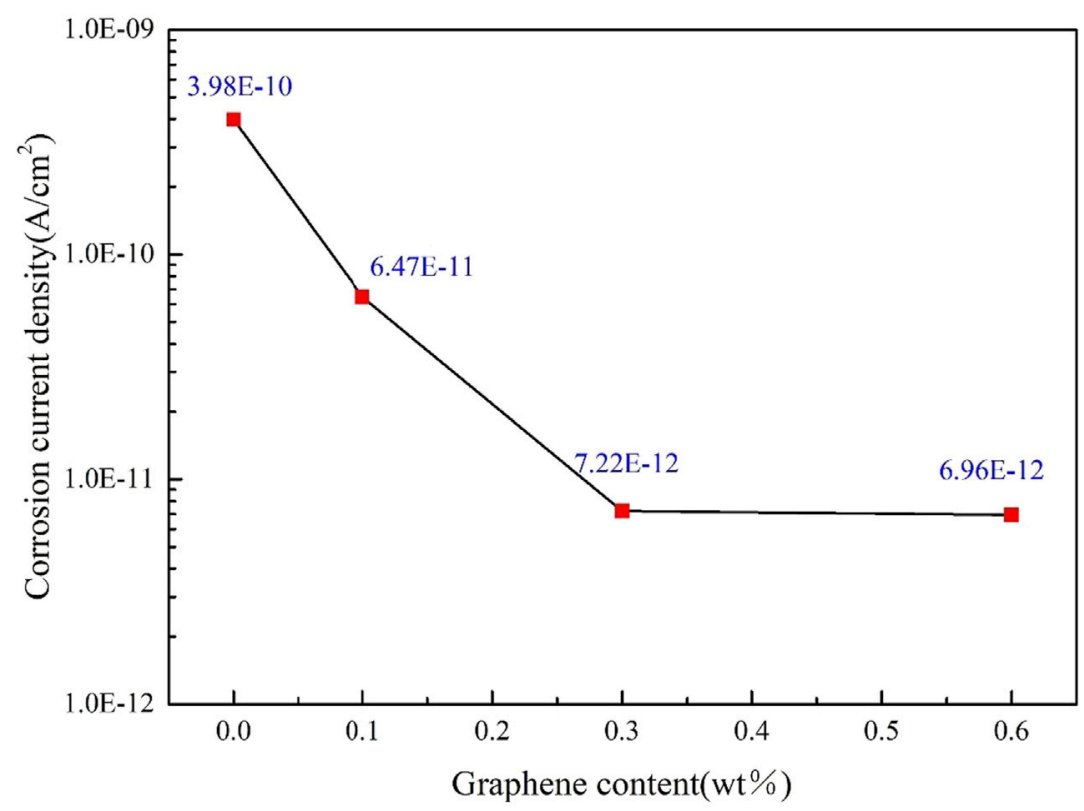

FIGURE 6 | Variation trend of corrosion current density of oily epoxy resin coating with different graphene content.

\section{A}

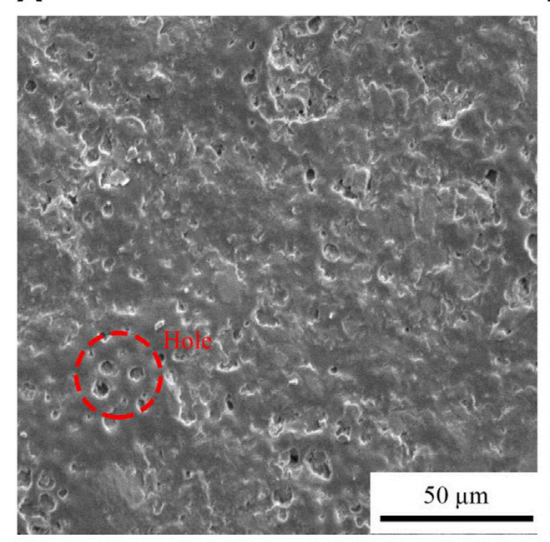

C

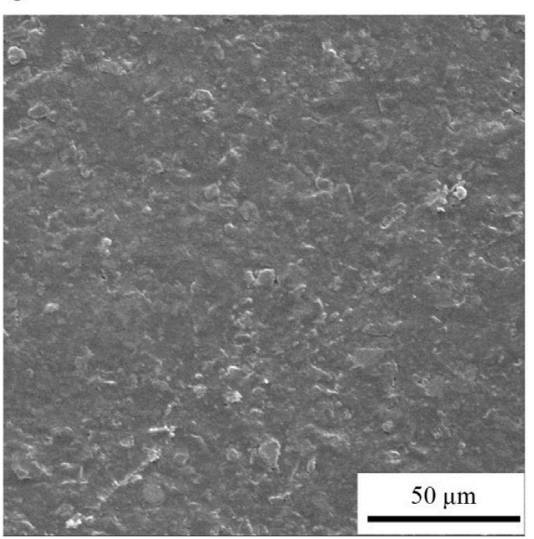

B

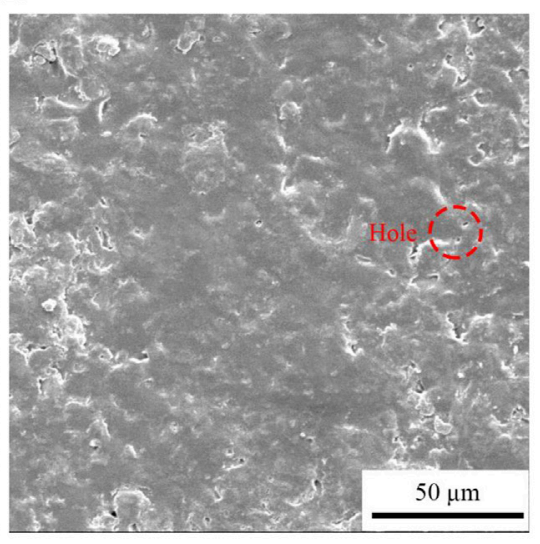

D

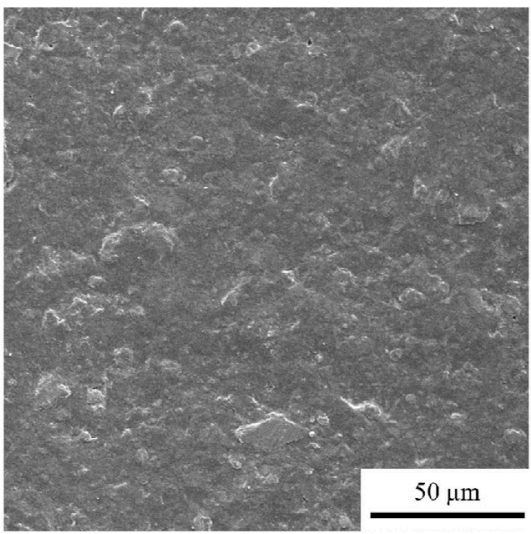

FIGURE 7| Corrosion morphology of modified oily epoxy resin coating with different graphene content: (A) G/OEP-0 wt\%, (B) G/OEP-0.1 wt\%, (C) G/OEP-0.3 wt $\%$, (D) G/OEP-0.6 wt\%. 
two orders of magnitude, from $3.98 \times 10^{-10} \mathrm{~A} / \mathrm{cm}^{2}$ to $6.96 \times$ $10^{-12} \mathrm{~A} / \mathrm{cm}^{2}$. Based on the analysis of Figure 4, it is believed that the addition of graphene reduces the pores of the coating, increases the diffusion resistance of the corrosive medium to the surface of the substrate, and improves the corrosion resistance of the coating. In addition, graphene will preferentially agglomerate inside the coating as the content increases. Although it still plays a shielding role for corrosive media, it reduces the corrosion inhibition effect. Therefore, the decline trend of the corrosion current density of G/OEP$0.6 \mathrm{wt} \%$ tends to be gentle.

\section{Analysis of Coating Corrosion Mechanism}

Figure 7 shows the morphology of modified oily epoxy resin coatings with different graphene content after corrosion. As shown in Figure 7A, before graphene is added, the corrosion of the coating is more serious and there are more holes. With the addition of graphene, it can be seen from Figure 7B that $0.1 \mathrm{wt} \%$ of graphene has improved the corrosion resistance of the coating, and the holes caused by corrosion are significantly reduced. When the graphene content in the coating reaches $0.3 \mathrm{wt} \%$ and 0.6 wt $\%$, Figures 7C,D show that after a period of electrochemical corrosion, there are almost no related holes caused by corrosion on the surface of the coating. And the coating surface is smoother, showing excellent anti-corrosion performance. This is also mutually corroborating the results of the potential polarization curve of the coating, indicating that the epoxy resin coating modified by graphene can provide good corrosion resistance for the substrate and avoid damage to the coating surface by corrosive media. And after adding the graphene content to $0.6 \mathrm{wt} \%$, the coating is least affected by corrosion and has good corrosion resistance.

Based on the analysis of relevant literature reports (Liao et al., 2017; Lu et al., 2018; Wu et al., 2018). If graphene is not added, the coating has relatively porous holes, which cannot well shield the penetration of corrosive media to the coating, so that the coating is greatly affected by corrosion. When a small amount of graphene is added for modification, the graphene is dispersed and arranged inside the coating, increasing the length of the corrosive medium penetration path. However, the coating and the substrate are affected by corrosion caused by $\mathrm{H}_{2} \mathrm{O}$ and $\mathrm{O}_{2}$ molecules and $\mathrm{Cl}^{-}$ions will still penetrate the coating during diffusion. When the content of graphene increases to $0.3 \%-0.6 \%$ $w t$, because the number of pores on the surface of the coating is reduced, not only the density of the graphene coating can be increased, but also the hydrophobicity of the coating will be enhanced, which make it difficult for the corrosive media to

\section{REFERENCES}

Chen, C., He, Y., Xiao, G., Zhong, F., Xia, Y., and Wu, Y. (2020). Graphic C3N4Assisted Dispersion of Graphene to Improve the Corrosion Resistance of Waterborne Epoxy Coating. Prog. Org. Coat. 139, 105448. doi:10.1016/ j.porgcoat.2019.105448

Chen, Y., Li, J., Yang, W., Gao, S., and Cao, R. (2019). Enhanced Corrosion Protective Performance of Graphene Oxide-Based Composite Films on AZ31 penetrate the interface between the coating and the substate, so that the corrosion resistance of the coating can be greatly improved.

\section{CONCLUSION}

The G/OEP coating was prepared on the surface of AZ31 magnesium alloy by brush coating technology. Graphene has fewer surface defects and is successfully doped into the coating. The G/OEP coating significantly improves the corrosion resistance of magnesium alloys. With the graphene content increases, the corrosion resistance of the coating is gradually improved. The corrosion current density of the G/OEP coating is reduced by two orders of magnitude, from $3.98 \times 10^{-10} \mathrm{~A} / \mathrm{cm}^{2}$ to $6.96 \times 10^{-12} \mathrm{~A} / \mathrm{cm}^{2}$. The graphene can fill the defects generally in the coating during the curing process to prevent substrate from penetration of corrosive medium caused by the density and hydrophobicity of coating are increased.

\section{DATA AVAILABILITY STATEMENT}

The original contributions presented in the study are included in the article/Supplementary Material, further inquiries can be directed to the corresponding author.

\section{AUTHOR CONTRIBUTIONS}

Conceptualization, ZG; methodology, CS; validation, DY and XZ; formal analysis, ZG, CS, and ZA; data curation, DY and XZ; writing-original draft preparation, $Z G, C S$, and $X Z$; writing - review and editing, ZG, CS, and ZA; supervision, ZG and $\mathrm{ZA}$; funding acquisition, ZG. All authors have read and agreed to the published version of the manuscript.

\section{FUNDING}

The present work is supported by the Scientific and Technological Research Program of Chongqing Science and Technology Bureau (Grant No. cstc2019jcyj-msxmX0761), the Scientific and Technological Research Program of Chongqing Municipal Education Commission (Grant No. KJQN201800731), the Scientific and Technological Research Program of Chongqing Jiaotong University (Grant No. 16JDKJC-A005).

Magnesium Alloys in 3.5 wt\% NaCl Solution. Appl. Surf. Sci. 493, 1224-1235. doi:10.1016/j.apsusc.2019.07.101

Chu, J. H., Tong, L. B., Wen, M., Jiang, Z. H., Wang, K. S., and Zhang, H. J. (2019). Graphene Oxide Film as a Protective Barrier for $\mathrm{Mg}$ alloy: Worse or Better Is Dependent on a Chemical Reduction Process. Carbon 145, 389-400. doi:10.1016/j.carbon.2019.01.037

Cui, G., Bi, Z., Zhang, R., Liu, J., Yu, X., and Li, Z. (2019). A Comprehensive Review on Graphene-Based Anti-Corrosive Coatings. Chem. Eng. J. 373, 104-121. doi:10.1016/j.cej.2019.05.034 
Deyab, M. A., De Riccardis, A., and Mele, G. (2016). Novel Epoxy/metal Phthalocyanines Nanocomposite Coatings for Corrosion protection of Carbon Steel. J. Mol. Liquids 220, 513-517. doi:10.1016/ j.molliq.2016.04.115

Ding, R., Chen, S., Lv, J., Gui, T.-J., Wang, X., Zhao, X.-D., et al. (2019). Review of Theoretical and Applied Research of Graphene in Anti-Corrosion Film and Organic Anti-Corrosion Coatings. Acta Chim. Sinica 77, 1140-1155. doi:10.6023/a19050174

Dong, Y., Ma, L., and Zhou, Q. (2013). Effect of the Incorporation of Montmorillonite-Layered Double Hydroxide Nanoclays on the Corrosion protection of Epoxy Coatings. J. Coat. Technol. Res. 10, 909-921. doi:10.1007/s11998-013-9519-x

Dziubińska, A., Gontarz, A., Dziubiński, M., and Barszcz, M. (2016). The Forming of Magnesium alloy Forgings for Aircraft and Automo-Tive Applications. Adv. Sci. Technol. Res. J. 10, 158-168. doi:10.12913/22998624/64003

Guo, L., Gu, C., Feng, J., Guo, Y., Jin, Y., and Tu, J. (2020). Hydrophobic Epoxy Resin Coating with Ionic Liquid Conversion Pretreatment on Magnesium alloy for Promoting Corrosion Resistance. J. Mater. Sci. Technol. 37, 9-18. doi:10.1016/j.jmst.2019.06.024

Hao, S. S., Sun, X. F., Song, W., Li, Z. M., and Qiu, J. (2018). Preparation and Properties of Graphene Modified Epoxy Resin Coating. China Surf. Eng. 31, 108-115. doi:10.11933/j.issn.1007-9289.20180120003

He, X.-L., Wei, Y.-H., Hou, L.-F., Yan, Z.-F., Guo, C.-L., and Han, P.-J. (2014). Corrosion Fatigue Behavior of Epoxy-Coated Mg-3Al-1Zn alloy in $\mathrm{NaCl}$ Solution. Rare Met. 33, 276-286. doi:10.1007/s12598-014-0278-3

Jin, F.-L., Li, X., and Park, S.-J. (2015). Synthesis and Application of Epoxy Resins: A Review. J. Ind. Eng. Chem. 29, 1-11. doi:10.1016/j.jiec.2015.03.026

Liao, Z., Zhang, T., Qiao, S., and Zhang, L. (2017). Preparation and Electrochemical Properties of Graphene/epoxy Resin Composite Coating. IOP Conf. Series: Earth Environ. 94, 012072. doi:10.1088/1755-1315/94/1/012072

Lu, C., Feng, C., Zhu, L., Jiang, L., Gao, G., Han, L., et al. (2018). "Graphene Modified Epoxy Coating Tubing Applied in the Water Injection wells," in Advances in Materials Processing, Beijing: Springer, 1075-1082. doi:10.1007/978-981-13-0107$0 \_102$

Ou, B., Wang, Y., and Lu, Y. (2020). A Review on Fundamentals and Strategy of Epoxy-Resin-Based Anticorrosive Coating Materials. Polym-Plast. Tech. Mat. 60, 1-25. doi:10.1080/25740881.2020.1819317

Rahman, M. M., Islam, M. M., Khan, M. M. R., Ong, H. R., Uddin, M. T., and Islam, M. A. (2019). IBA-Modified Gypsum-Containing Epoxy Resin Coating for Rebar: Corrosion Performance and Bonding Characteristics. Int. J. Plast. Technol. 23, 20-28. doi:10.1007/s12588-019-09238-3

Ramalingam, V. V., Ramasamy, P., Kovukkal, M. D., and Myilsamy, G. (2019). Research and Development in Magnesium Alloys for Industrial and Biomedical Applications: A Review. Met. Mater. Int. 26, 409-430. doi:10.1007/s12540-01900346-8

Shi, H. W., Liu, F. C., and Han, E.-H. (2012). Improving Corrosion Resistance of Epoxy Coatings Modified with Silane Monomers on AZ31D Magnesium Alloy. Can. Metallurgical Q. 51, 485-490. doi:10.1179/1879139512y.0000000017

Siva, T., Kamaraj, K., and Sathiyanarayanan, S. (2014). Epoxy Curing by Polyaniline (PANI) - Characterization and Self-Healing Evaluation. Prog. Org. Coat. 77, 1095-1103. doi:10.1016/j.porgcoat.2014.03.019

Song, G., and Atrens, A. (2003). Understanding Magnesium Corrosion-A Framework for Improved Alloy Performance. Adv. Eng. Mater. 5, 837-858. doi:10.1002/adem.200310405

Song, G. (2005). Recent Progress in Corrosion and Protection of Magnesium Alloys. Adv. Eng. Mater. 7, 563-586. doi:10.1002/adem.200500013

Song, J., She, J., Chen, D., and Pan, F. (2020). Latest Research Advances on Magnesium and Magnesium Alloys Worldwide. J. Magnesium Alloys 8, 1-41. doi:10.1016/j.jma.2020.02.003
Tekumalla, S., Seetharaman, S., Almajid, A., and Gupta, M. (2014). Mechanical Properties of Magnesium-Rare Earth Alloy Systems: A Review. Metals 5, 1-39. doi:10.3390/met5010001

Wang, M.-H., Li, Q., Li, X., Liu, Y., and Fan, L.-Z. (2018). Effect of OxygenContaining Functional Groups in Epoxy/reduced Graphene Oxide Composite Coatings on Corrosion protection and Antimicrobial Properties. Appl. Surf. Sci. 448, 351-361. doi:10.1016/j.apsusc.2018.04.141

Wu, W., Liu, J., Li, X., Hua, T., Cong, X., Chen, Z., et al. (2018). Incorporation Graphene into Sprayed Epoxy-Polyamide Coating on Carbon Steel: Corrosion Resistance Properties. Corrosion Eng. Sci. Technol. 53, 625-632. doi:10.1080/ $1478422 x .2018 .1521590$

Xia, W., Wang, T., Song, L., Gong, H., Guo, H., Fan, X. L., et al. (2018). Graphene/Epoxy Composite Coating Damage Under Gamma-Ray Irradiation and Corrosion protection. J. Inorg. Mater. 33, 35-41. doi:10.15541/jim20170143

Xie, Y. K., Liu, W. Q., Liang, L. Y., Liu, C. H., He, S., Zhang, F. Y., et al. (2019). Enhancement of Anticorrosion Property and Hydrophobicity of Modified Epoxy Coatings with Fluorinated Polyacrylate. Colloid Surf. A-Physicochem. Eng. Asp. 579, 10. doi:10.1016/j.colsurfa.2019.123659

Ye, Y., Yang, D., Zhang, D., Chen, H., Zhao, H., Li, X., et al. (2020). POSSTetraaniline Modified Graphene for Active Corrosion Protection of EpoxyBased Organic Coating. Chem. Eng. J. 383, 123160. doi:10.1016/ j.cej.2019.123160

Zeng, Z., Stanford, N., Davies, C. H. J., Nie, J.-F., and Birbilis, N. (2018). Magnesium Extrusion Alloys: A Review of Developments and Prospects. Int. Mater. Rev. 64, 27-62. doi:10.1080/09506608.2017.1421439

Zhang, Z., Zhang, W., Li, D., Sun, Y., Wang, Z., Hou, C., et al. (2015). Mechanical and Anticorrosive Properties of Graphene/Epoxy Resin Composites Coating Prepared by Iin-Ssitu Method. Int. J. Mol. Sci. 16, 2239-2251. doi:10.3390/ ijms16012239

Zhao, Y., Xie, Y., Hui, Y. Y., Tang, L., Jie, W., Jiang, Y., et al. (2013). Highly Impermeable and Transparent Graphene as an Ultra-Thin Protection Barrier for Ag Thin Films. J. Mater. Chem. C 1, 4956. doi:10.1039/c3tc30743c

Zhou, S., Wu, Y., Zhao, W., Yu, J., Jiang, F., and Ma, L. (2018). Comparative Corrosion Resistance of Graphene Sheets with Different Structures in Waterborne Epoxy Coatings. Colloids Surf. A: Physicochemical Eng. Aspects 556, 273-283. doi:10.1016/j.colsurfa.2018.08.045

Ziat, Y., Hammi, M., Zarhri, Z., and Laghlimi, C. (2020). Epoxy Coating Modified with Graphene: A Promising Composite against Corrosion Behavior of Copper Surface in Marine Media. J. Alloy. Compd. 820, 6. doi:10.1016/ j.jallcom. 2019.153380

Conflict of Interest: The authors declare that the research was conducted in the absence of any commercial or financial relationships that could be construed as a potential conflict of interest.

Publisher's Note: All claims expressed in this article are solely those of the authors and do not necessarily represent those of their affiliated organizations, or those of the publisher, the editors and the reviewers. Any product that may be evaluated in this article, or claim that may be made by its manufacturer, is not guaranteed or endorsed by the publisher.

Copyright (c) $2021 \mathrm{Gao}$, Sun, Du, Yang, Zhang and An. This is an open-access article distributed under the terms of the Creative Commons Attribution License (CC BY). The use, distribution or reproduction in other forums is permitted, provided the original author(s) and the copyright owner(s) are credited and that the original publication in this journal is cited, in accordance with accepted academic practice. No use, distribution or reproduction is permitted which does not comply with these terms. 